\title{
Energy saving effects of integrated lighting utilizing daylight
}

\author{
Mitsuru SAITO*, Kanji SAKAI* and Kiyotaka ENDO*
}

\begin{abstract}
This paper presents the energy saving effects in a building having automatically controlled lighting utilizing daylight inside perimeter zone.

We have developed a computer program that enables to calculate capital and energy cost of a building in order to estimate the energy saving effects, and calculated many cases under various conditions, such as four types of window ratio to wall $(20 \%, 35 \%, 50 \%, 65 \%)$, three operation types of venetian blind, etc.

Finally we estimated these energy saving effiects by using a two-dimensional vector on a graph, on which the abscissa shows capital cost required and ordinate energy cost. By means of this yector on the graph, building owners can easily understand the energy saving effects of an automatically controlled lighting system utilizing daylight.
\end{abstract}

\section{Introduction}

The energy consumption increases in a building which has large window area. As the large window area causes increased summer heat gain and winter heat loss, small window area buildings are usually recommended. However this may be changed if the artificial lighting inside perimeter zone is turned off or controlled automatically utilizing daylight.

Some papers about daylight utilization in interiors have been published ${ }^{1) \sim 5)}$. We have developed a computer program which enables us to calculate capital and energy cost of a building in order to estimate the energy saving effects, and many cases have been calculated under various conditions, such as four types of window area ratio to outside wall $(20 \%, 35 \%, 50 \%, 65 \%)$, three operation types of venetian blind, etc.

Finally we estimated these energy saving effects using a two-dimensional vector on a graph, on which the abscissa shows capital cost required and ordinate energy cost.

\section{Evaluation method of energy conservation techniques using two-dimensional vectors on a graph}

In order to evaluate various energy conservation techniques, the effect of each technique is shown as a two-dimensional vector on a graph, where the abscissa shows the capital cost required and the ordinate energy cost. Therefore we call this vector a thermal economics vector.

* Building Services Engineering Department, Head Office, Ohbayashi-Gumi, Ltd. 12-5, Uchikanda 2chome, Chiyoda-ku, Tokyo 101, Japan, Tel. (03) 292111

A part of this paper was described in J. Illum. Engng. Inst. Jpn. 65-4 (1981).

\subsection{Steps of procedure to show} economics vector on a graph

(1) First, we calculate the capital cost required $I_{b}$, and energy $\operatorname{cost} R_{0}$, of the building in which no energy conservation techniques are adopted, using the computer program which we have developed.

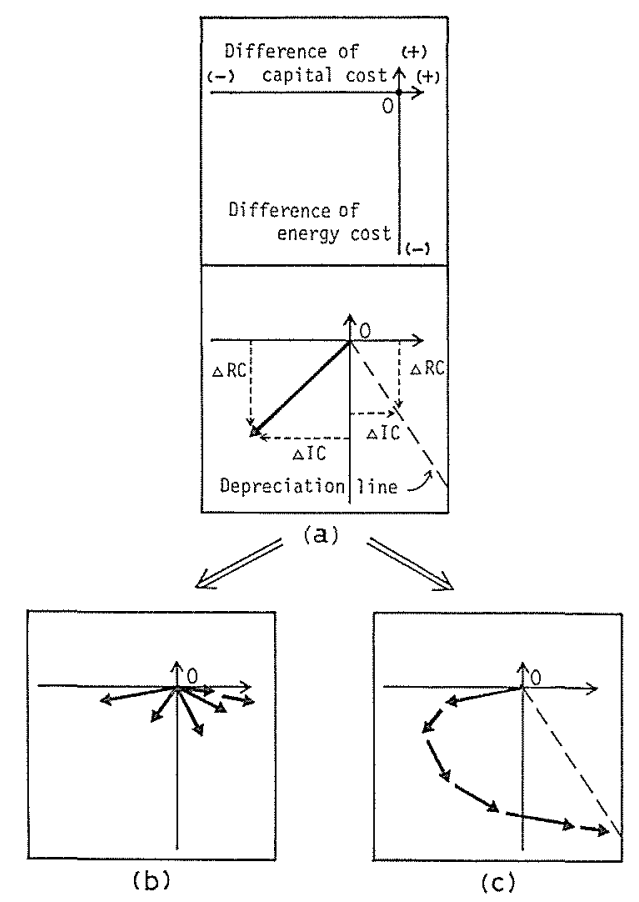

Fig. 1 Evaluation procedure using thermal economics vector.

(a) Assignment of the original building to the origin.

(b) Evaluation of the effect of each technique.

(c) Evaluation of the accumulated effect of some selected techniques. 
This original building is assigned to the origin on the graph (Fig. 1 (a)).

(2) Secondally, in order to evaluate each energy conservation technique individually, we calculate both costs, $I_{i}$ and $R_{i}$, of the building in which each technique is adopted, as well as the original building. The cost differences between each energy conservation building and the original building are calculated as follows,

$$
\triangle I C_{i}=I_{i}-I_{0}, \triangle R C_{i}=R_{i}-R_{0}
$$

$i$ : suffix showing each energy conservation technique

and each vector is drawn on the graph as Fig. 1 (b)

(3) Finally, in order to evaluate the accumulated effect of some selected techniques, we calculate both costs of the building in which some techniques are adopted, and the cost differences are as follows,

$$
\triangle I C_{j}=I_{j}-I_{j-1}, \triangle R C_{j}=R_{j}-R_{j-1}
$$

where, $j$ : suffix showing the number of adopted techniques

and the combined vector is drawn on the graph as Fig. 1 (c).

\subsection{Evaluation method using depreciation period}

When an energy conservation technique is adopted in a building, the increase of the average annual expenditure $\Delta I$, is calculated using the average interest model of engineering economy as eq. (3). Similarly, the decrease of the average annual expenditure $\Delta R$, is calculated as eq. (4).

$$
\begin{aligned}
& \Delta I=\Delta I C \cdot(1-r) \frac{1}{T}+\Delta I C \cdot r \cdot i+\Delta I C \cdot(1-r) \cdot \\
& i_{2}\left(\frac{T+1}{T}\right) \\
& \Delta R=\Delta R C \cdot \frac{(1+j)^{T}-1}{T \cdot j}(\text { when } j=0 \\
& \Delta R=\Delta R C)
\end{aligned}
$$

$$
\begin{aligned}
& r=0 \text { and } \Delta I=\Delta R \text { yields, } \\
& \qquad \Delta I C\left\{1+\frac{i(T+1)}{2}=\Delta R C \cdot \frac{(1+j)^{T}-1}{j}\right.
\end{aligned}
$$

Depreciation period $T$, can be calculated from eq. (5), and the gradient $\triangle R C / \triangle I C$, can be calculated for any value of $\mathrm{T}$. By drawing the depreciation line with calculated gradient on the graph, as Fig. 1 (a), depreciation period of each energy conservation technique can be found easily.

\section{Calculation of energy consum- ption within a building ${ }^{6)}$}

According to the results of research for the amount of annual energy consumption within commercial buildings, the composition of annual energy consumption within a building is shown as Fig. 2.

Utilizing daylight inside perimeter zone decreases lighting and cooling energy consumption in summer, but increases heating energy consumption in winter. Therefore, to evaluate daylighting system, building total energy consumption (especially airconditioning and lighting energy consumption) must be analyzed.

For this purpose building total primary energy consumption in a year can be calculated using computer program which we have developed as follows.

\subsection{Air-conditioning}

(1) Energy consumption of refrigerator and boiler ${ }^{93}$

Using hour-by-hour thermal loads calculated by response-factor and weighting-factor method, the primary energy consumption of refrigerator and boiler in a year $E_{c}$ and $E_{h}$, is calculated as follows,

$$
\begin{aligned}
& E_{c}=\sum_{i} \frac{L_{c i}}{C O P_{i} \cdot \eta_{e}} \quad(\mathrm{kcal} / \mathrm{a}) \\
& E_{h}=\sum_{i} \frac{L_{h i}}{\eta_{B}} \quad(\mathrm{kcal} / \mathrm{a}) \\
& \text { where, } \quad i \text { : suffix showing time } \\
& L_{c i}(\mathrm{kcal} / \mathrm{h}): \text { cooling load } \\
& L_{h i}(\mathrm{kcal} / \mathrm{h}) \text { : heating load } \\
& \mathrm{COP}_{i} \quad \text { : coefficient of performance of }
\end{aligned}
$$

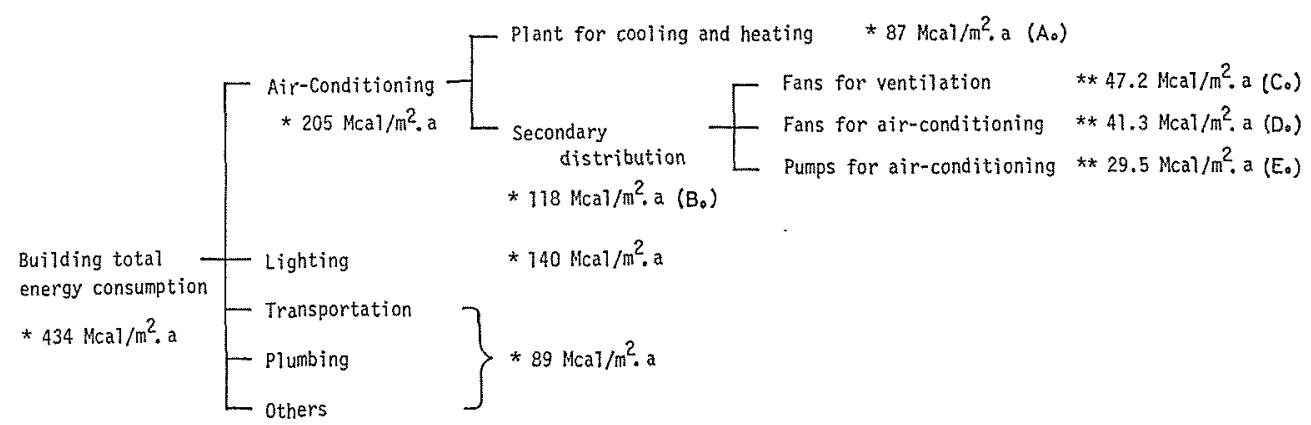

Fig. 2 Composition of energy consumption within a conventional commercial building.

- Each number is the primary energy consumption devided by the gross floor area.

- The suffix "*" shows the results by Ref. ( 7$)$, (8).

- The suffix "*:" shows the results obtained from the analysis of several selected commercial buildings. 
chiller (3.0 in all season)

$\eta_{*} \quad$ : efficiency of generator (0.351)

(2) Secondary HVAC distribution energy consumption

Assuming that the energy consumption of fans and pumps for air-conditioning is in proportion to the summer peak load, $D_{0}$ and $E_{0}$ in Fig. 2 are corrected as follows,

$$
\begin{aligned}
& D_{1}=\frac{L_{1}}{L_{0}} \cdot D_{0}\left(\mathrm{Mcal} / \mathrm{m}^{2} \cdot \mathrm{a}\right) \\
& E_{1}=\frac{L_{1}}{L_{0}} \cdot E_{0}\left(\mathrm{Mcal} / \mathrm{m}^{2} \cdot \mathrm{a}\right)
\end{aligned}
$$

where, $L_{0}\left(\mathrm{kcal} / \mathrm{m}^{2} \cdot \mathrm{h}\right)$ : the standard peak summer load (assumed to be 100)

$L_{1}\left(\mathrm{kcal} / \mathrm{m}^{2} \cdot \mathrm{h}\right)$ : the actually calculated peak summer load

Ultimately, the primary energy consumption of distribution system is calculated by multiplying $C_{0}$, $D_{1}$ and $E_{1}$ by the gross floor area.

\subsection{Lighting}

The primary consumption for lighting $E_{l}$, is calculated as follows,

$$
\begin{aligned}
& E_{l}=\sum_{i} \sum_{j} W_{i} \times 10^{-3} \times A R_{i} \times r_{i j} \times C F \quad \cdots \cdots \cdots \cdots(10) \\
& \text { where, } i \text { : suffix showing zone } \\
& j \text { : suffix showing time } \\
& W_{i}\left(\mathrm{w} / \mathrm{m}^{2}\right) \text { : lighting output in } i \text { zone } \\
& A R_{i} \quad \text { : floor area of } i \text { zone } \\
& r_{i j} \quad: \text { fraction of lights turned on }
\end{aligned}
$$

\subsection{Elevator, plumbing system and others}

The primary energy consumption of elevator, plumbing system and others is calculated by multiplying $G_{0}$ in Fig. 2 by the gross floor area.

\section{Calculation of the capital cost and energy cost}

\section{1 The capital cost of architectural elements}

The unit costs of elements such as roof wall, outside wall, window surroundings, inside wall, eaves, and so on are prepared in the computer program as

\begin{tabular}{|c|c|c|}
\hline Element & Material composition & $\begin{array}{l}\text { Unit cost } \\
\left.\text { (yen } / \mathrm{m}^{2}\right)\end{array}$ \\
\hline Roofing & $\begin{array}{l}\text { Lightweight concrete } \\
\text { Asphalt water proofing } \\
\text { Heavyweight concrete } \\
\text { Expanded polystyrene }(25 \mathrm{~mm}) \\
\text { Plaster board } \\
\text { Rockwool board }\end{array}$ & 21,490 \\
\hline Outside wall & $\begin{array}{l}\text { Heavyweight concrete } \\
\text { Expanded polystyrene }(25 \mathrm{~mm}) \\
\text { Plaster board }\end{array}$ & 24,120 \\
\hline Inside wall & $\begin{array}{l}\text { Cement mortar } \\
\text { Heavyweight concrete }\end{array}$ & 19,150 \\
\hline $\begin{array}{l}\text { Window } \\
\text { surrounings }\end{array}$ & $\begin{array}{l}\text { Glazing } \\
\text { Aluminum sash } \\
\text { Venetian blind }\end{array}$ & 59,730 \\
\hline Eaves & Heavyweight concrete & 10,000 \\
\hline
\end{tabular}
Table 1 .

The capital cost of each element is calculated by multiplying its unit cost by its area.

\begin{tabular}{|c|c|c|c|c|}
\hline Element & \multicolumn{2}{|l|}{ Standard load } & $\begin{array}{c}\text { Unit cost } 1 \\
\left(\text { yen } / \mathrm{m}^{2}\right)\end{array}$ & $\begin{array}{c}\text { Unit cost } 2 \\
\left(\text { yen } / \mathrm{m}^{2}\right)\end{array}$ \\
\hline \multirow{2}{*}{$\begin{array}{l}\text { Plant } \\
\text { for cooling }\end{array}$} & \multirow{2}{*}{$\begin{array}{l}\text { Summer peak load } \\
\left(\mathrm{kcal} / \mathrm{m} .{ }^{2} \mathrm{~h}\right)\end{array}$} & 100 & 5,681 & 3,542 \\
\hline & & 150 & 7,142 & 4,938 \\
\hline \multirow{2}{*}{$\begin{array}{l}\text { Plant } \\
\text { for heating }\end{array}$} & \multirow{2}{*}{$\begin{array}{l}\text { Winter peak load } \\
\qquad\left(\mathrm{kcal} / \mathrm{m}^{2} \cdot \mathrm{h}\right)\end{array}$} & 80 & 1,047 & 811 \\
\hline & & 150 & 1,553 & 1,312 \\
\hline \multirow{2}{*}{$\begin{array}{l}\text { Secondary } \\
\text { AHU system }\end{array}$} & \multirow{2}{*}{$\begin{array}{l}\text { Maximum blowing } \\
\text { volume } \\
\qquad\left(\mathrm{m}^{3} / \mathrm{m}^{2} \cdot \mathrm{h}\right)\end{array}$} & 13.6 & 9,794 & 8,106 \\
\hline & & 20.5 & 11,864 & 10,589 \\
\hline \multirow{2}{*}{$\begin{array}{l}\text { Secondary } \\
\text { FCU system }\end{array}$} & \multirow{2}{*}{$\begin{array}{l}\text { Summer of winter } \\
\text { peak load } \\
\left(\mathrm{kcal} / \mathrm{m}^{2} \cdot \mathrm{h}\right)\end{array}$} & 112.5 & 18,737 & 18,590 \\
\hline & & 168.8 & 21,390 & 21,161 \\
\hline
\end{tabular}

\subsection{The capital cost of air-condition- ing equipments}

The unit costs of elements of air-conditioning equipments are prepared in the computer program as Table 2, and corrected by thermal loads calculated by the program and the gross floor area of the building. The capital cost of each element is calculated by mutiplying the corrected unit cost by its zone floor area.

Table 1 Some examples of material composition and unit cost of architectural elements

Table 2 Some examples of unit cost of conventional air-conditioning system's elements

* Unit cost 1 is the cost in the case of gross floor area $10,000 \mathrm{~m}^{2}$

* Unit cost 2 is the cost in the case of gross floor area $50,000 \mathrm{~m}^{2}$.

* The unit $\mathrm{m}^{2}$, in each dimension shows the unit airconditioning floor area in the case of Plant for cooling and heating, the unit floor area of interior zone in the case of secondary AHU system, and the unit floor area of perimeter zone in the case of secondary FCU system.

Table 3 Some examples of unit cost of electrical equipment

\begin{tabular}{l|c}
\hline \multicolumn{1}{c|}{ Element } & Unit cost (yen/kVA) \\
\hline Transformation work & 15,180 \\
\hline Feeder work & 7,038 \\
\hline $\begin{array}{l}\text { Mechanical work } \\
\text { Lighting fixture } \\
\text { and wiring work }\end{array}$ & 12,719 \\
\hline
\end{tabular}




\subsection{The capital cost of electrical equipments}

The unit costs of electrical equipments are shown in Table 3. The cost of artificial lighting controller equipped near the each window is two hundred and fifty thousand yen and the increase of ballast cost for step light control is four thousand yen.

\subsection{The annual energy cost}

The primary energy consumption of boilers calculated in section 3 is converted into the kerosene consumption, and the primary energy consumption of other equipments is converted into the electric power consumption. The building total annual energy cost $E_{t}$, is calculated as follows,

$$
\begin{aligned}
& E_{t}=E_{k t}+E_{e t} \\
& E_{k t}=\sum_{j} \frac{E_{k j}}{C F_{k}} \times C_{k} \\
& E_{c t}=\sum_{j}\left(\frac{E_{e i j}}{C F_{e}} \times C_{e j}+W \times C E\right) \\
& E_{k t}(\text { yen/a) : the annual cost of the } \\
& E_{\theta t}(\text { yen/a) : the annual cost of the }
\end{aligned}
$$
$E_{e j}(\mathrm{kcal} / \mathrm{month})$ : the primary energy consumption of other equipments

\section{Simulation procedure of artifi- cial lighting control inside perimeter zone}

\section{1 Control procedure of artificial lighting}

The procedure of artificial lighting control inside perimeter zone utilizing daylight is shown in Fig. 3. We assumed the daylight illuminance $E_{d}$ is equal to the average illuminance in the case that all luminaires in a room are turned on.

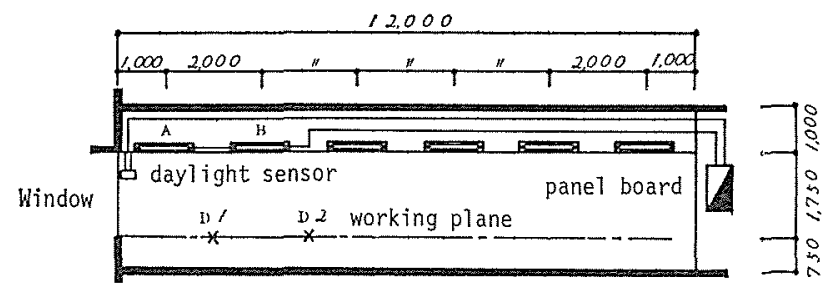

Fig. 3 Control procedure of artificial lighting inside perimeter zone.

$A, B$ : Controlled luminaires utilizing daylight (two 40-w fluorescent lamps)

D1 : selected point in the case of one row turning on/off or turning on/off plus step light control. (the distance from window is $2 \mathrm{~m}$ )

D2 : selected point in the case of two rows turning on/off or turning on/off plus step light control (the distance from window is $4 \mathrm{~m}$ )

Control procedure of artificial lighting inside perimeter zone: (Turning on/off system)

* If the daylight illuminance at point $D 1$ exceeds $E d$ lux, luminair $A$ is turned off in the case of one row turning on/off.

* If the daylight illuminance at point D1 exceeds $E d$ lux, luminaire $A$ and $B$ are turned off in the case of two rows turning on/off. (Turning on/off plus step light control system)

* If the daylight illuminance at point $D 1$ exceeds Ed lux, luminair $A$ is turned off and in the case exceeding a half of $E d$ the light output of luminair $A$ is reduced to a half.

* If the daylight illuminance at point $D 1$ exceeds $E d$ lux, luminair $A$ and $B$ are turned off and in the case of exceeding a half of Ed the light output of liminair $A$ and $B$ is reduced to a half.

where, Ed: the daylight illuminance deciding turning on or off.

If we use coverless recessed luminaires using two $40 \mathrm{~W}$ fluorescent lamps, we can calculate utilization factor $U$ approximately as follows,

$U=0.505+0.674 \log R I-0.258(\log R I)^{2} \cdots \cdots(12)$

$R I$ : Room index

The above formula was derived by applying least square method to the curve shown in Fig. 4.

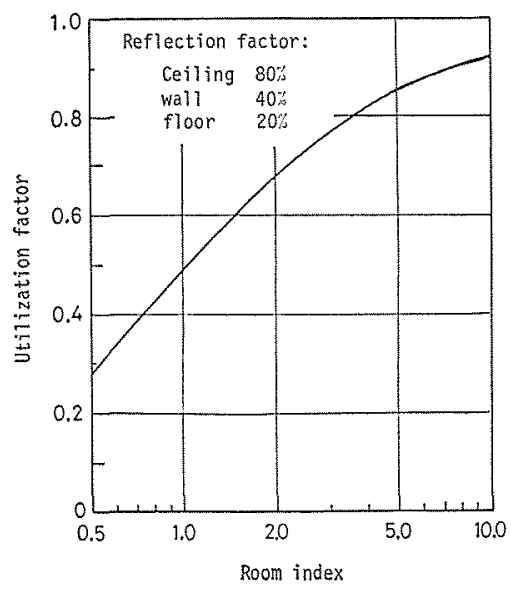

Fig. 4 The atilization factor of coverless recessed luminair $(40 W \times 2)$. 


\subsection{Calculation method of daylight illuminance in the interior}

We supposed three operation types of Venetian blind, of which slat reflection factor is about $60 \%$ and the ratio of slat width to slat pitch is 1.17 , for the shading device.

(1) Automatically controlled operation

Venetian blinds are driven down automatically when direct sunlight is incident in interiors. The angle of the slats is constantly set to $30^{\circ}$.

(2) Manual operation once a day

Venetian blinds are manipulated by building occupants at certain time once a day in accordance with window orientation. The angle of slats is set to $90^{\circ}$ when direct sunlight is not incident. The example of manipulation is shown in Fig. 5.

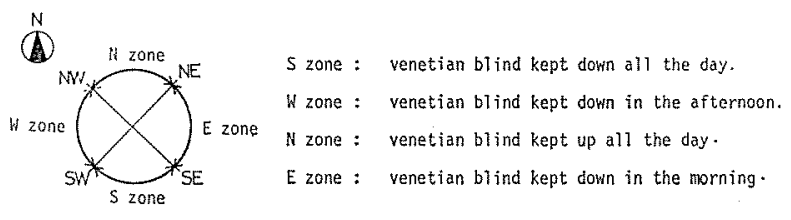

Fig. 5 Manual operation pattern of venetian blind.

(3) No up/down manipulation in the daytime

Venetian blinds are kept down in the daytime. The angle of slats is adjusted to $30^{\circ}$ for sunny days and to $90^{\circ}$ for cloudy days.

The weather, sunny or cloudy, is distinguished by direct normal sunlight illuminance.

We used 18,000 lux ${ }^{10}$ as this distinguishing illuminance.

The daylight illuminance in interiors was calculated as follows,

(a) Cloudy day'11)12)

In the case of cloudy day daylight factor was very convenient to predict daylight illuminance at the selected point. Therefore we calculated daylight factor under next conditions.

* The luminance ratio of venetian blind to the sky luminance is 0.08 .

* The luminance ratio of eaves to the sky luminance is 0.03 . (concrete reflection factor is $30 \%$ )

(b) Sunny day

In the case of sunny day we can't use daylight factor. The calculation method enabling daylight illuminance in interiors with venetian blind under direct sunlight is not developed. Then we calculated as shown below.

* Effective luminance of venetian blind is calculated by using luminance coefficient studied by Matsuura ${ }^{13)}$

* Direct daylight illuminance at the selected point is calculated by using effective luminance of venetian blind and configuration factor of window.

We assumed that the direct sunlight illuminance of window surface is six times as much as skylight illuminance ${ }^{14)}$.

* Indirect daylight illuminance is uniform in in- teriors. The upper component of daylight passing through slats of venetian blind is one and half times as much as lower component.

\subsection{Annual daylight illuminance data ${ }^{15) 16}$}

Daylight illuminance data throughout a year doesn't exist in Japan. We corrected solar radiation data called as HASP/ACLD/7302 which is prepared by the Society of Heating, Air-Conditioning and Sanitary Engineers of Japan, because original sky radiation data is considerably smaller than actual state. Then we converted sky radiation into daylight illuminance using conversion coefficient shown below.

(1) Conversion coefficient $C_{n}$ from direct solar radiation into direct sunlight illuminance

$$
\begin{aligned}
& C_{D}=27.8 \sin h+95 \quad(1 \mathrm{~m} / \mathrm{W}) \ldots \ldots \ldots \ldots \ldots \ldots(13) \\
& h: \quad \text { solar altitude }
\end{aligned}
$$

(2) Conversion coefficient $C_{d}$ from sky radiation into skylight illuminance

$$
C_{d}=7.18 \sin h+115.5 \quad(1 \mathrm{~m} / \mathrm{W})
$$

Also we assumed that solar radiation data during a month distributes uniformly evenly between $R_{t}-\sigma_{t}$ and $R_{t}+\sigma_{t}$ in order to reduce calculation time of computer. $R_{t}$ is mean value of solar radiation and $\sigma_{t}$ standard deviation.

\subsection{The annual reduction of electric energy consumption caused by integrated lighting}

We can calculate the annual reduction of electric energy consumption by artificial lighting using previously mentioned procedure. The calculating formula is shown below.

Energy saved by daylight

$$
\left.=\sum_{i} \sum_{j}\left(\Sigma S_{0} \times W_{o}\right) \times D_{w} \times R_{o f f} \times 1.15\right) \times 10^{-3}
$$

\section{(1)}

where, $S_{0}\left(\mathrm{~m}^{2}\right)$ : total area of perimeter zone connected with artificial lighting control utilizing daylight

$W_{o}\left(\mathrm{w} / \mathrm{m}^{2}\right)$ : lighting output in perimeter zone $D_{w}$ : working days per month (25 days)

$R_{o f f}:$ ratio of turned off or dimmed hours to full turned on hours

1.15 : ballast loss factor of fluorescent lamp

$j$ : suffix showing month

$j$ : suffix showing time $(9-17$ o'clock)

\section{The simulated example of energy consumption and saved energy by utilizing daylight}

We examined annual energy consumption and saved energy by daylighting in a model building of 
Table 4 Conditions for the simulation

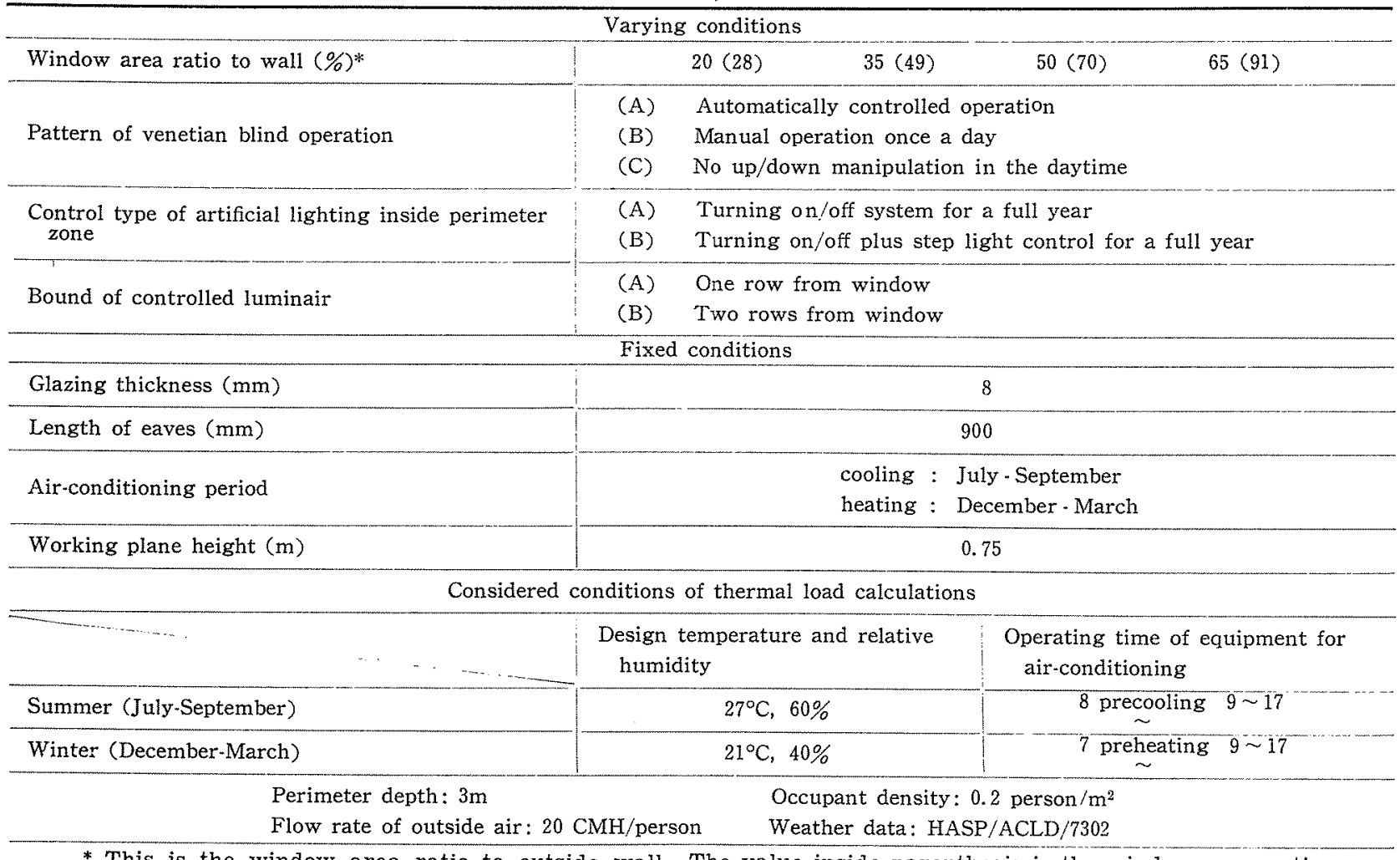
* This is the window area ratio to outside wall. The value inside parenthesis is the window area ratio
viewed from the inside of the room.

(i)

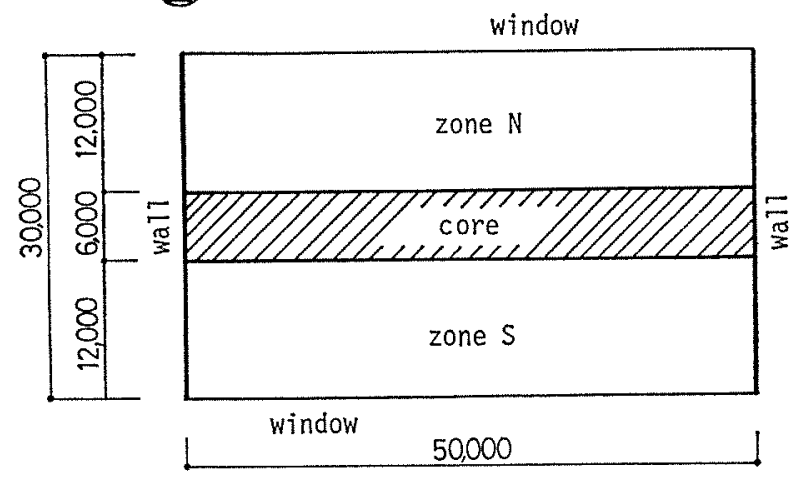

Fig. 6 Model building

Location: Tokyo

Outline of architecture:

10 stories, gross floor area $15,000 \mathrm{~m}^{2}$, rentable ratio $80 \%$

(outside wall)

heavyweight concrete

expanded polystyrene

plaster board

(core inside wall)

cement mortar

heavyweight concrete

cement mortar

Luminair: Coverless recessed type using two 40-w fluorescent lamps, lighting output without ballast loss $20 \mathrm{w} / \mathrm{m}^{2}$, average illuminance on the working plane 1,000 lux at lamp fux 6,000 lumen per luminair and maintenance factor 0.75 which outline is shown in Fig. 6. The various conditions for the simulation of a model building is shown in Table 4 . The calculated results, such as total energy consumption, cooling load, heating load, saved energy of artificial lighting and thermal economics vector, are shown in Fig. 7 and Fig. 8 .

We assumed that the type of operation of the blind is no up/down when automatic control of artificial lighting inside perimeter zone is not adopted.

\section{Results}

(1) Energy saving effect of artificial lighting inside perimeter zone increases as a building has large window. However there is little difference between $50 \%$ and $65 \%$ of window area ratio to wall area. Because the effective height at the window area ratio $65 \%$ is the same as the case of $50 \%$. In addition, the automatically controlled blind operation is most effective in three operation types. The second is manual operation type once a day.

(2) Cooling load is reduced and heating load is increased by artificial lighting control inside perimeter zone utilizing daylight.

(3) When the artificial lighting is turned off utilizing daylight, the total primary energy consumption of a building decreases. Also the primary energy consumption increases in proportion to the window area even though the artificial lighting inside perimeter zone is turned off. However there is an exception in the case that two rows of luminaire inside perimeter zone are turned off and blind is automatically controlled. 


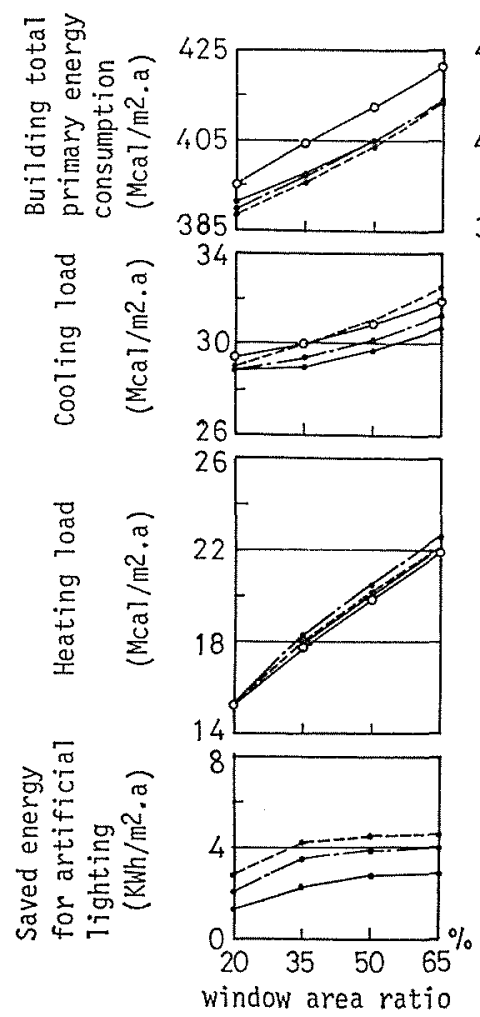

(a)
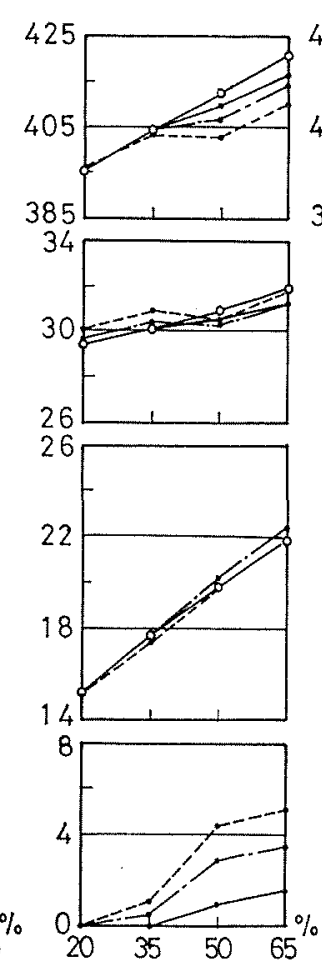

window area ratio

(b)
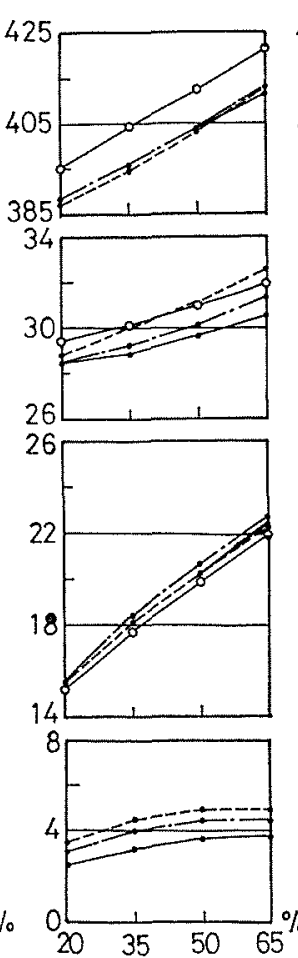

window area ratio

(c)
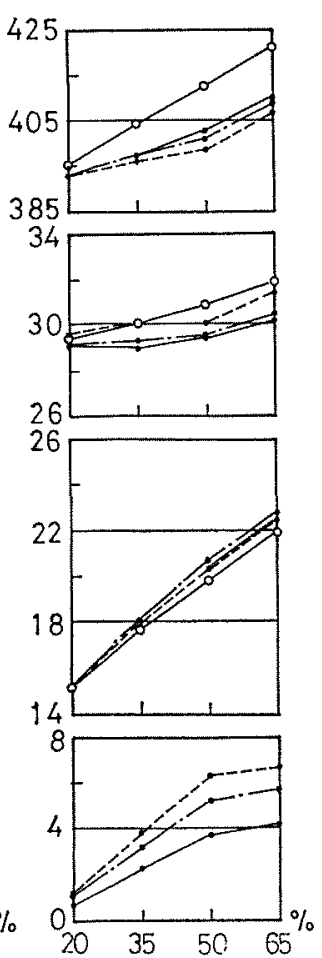

window area ratio

(d)

Fig. 7 Simulated results of a model building

(a) Turning on/off system (one row)

(b) Turning on/off system (two rows)

(c) Turning on/off plus step light control system (one row)

(d) Turning on/off plus step light control system (two rows)

Automatically controlled operation of venetian blind

-.- Manual operation once a day of venetian blind

- No up/down manipulation of venetian blind

No control of artificial lighting

- Control of artificial lighting utilizing daylight

In this exceptional case the total primary energy consumption of a building with window area ratio $50 \%$ to wall is less than $35 \%$ because of the large difference of saved energy for artificial lighting utilizing daylight. (see Fig. 7) However a building with window area ratio $50 \%$ to wall is much expensive than $35 \%$ because the cost of window surroundings and air-conditioning equipment increases. The difference of capital cost is about twenty-seven million yen.

(4) In the case of turning on/off plus step light control system of artificial lighting, saved energy for artificial lighting becomes larger than turning on/off system. Also the reduction of the total primary energy consumption using step light control system is about $0.2-0.8 \%$ in the case of one row control of luminaire and $0.7-1.7 \%$ in the case of two rows control of luminaire.

(5) We got next results by thermal economics vectors.

(a) The automatically controlled operation type of venetian blind is most effective as for energy conservation, but most expensive as for capital cost.

The increase of capital cost in the case of manual operation type once a day and no up/down manipulation type in the daytime is small, therefore daylight utilization in interiors should be considered.

(b) If we add the step light control system to the turning on/off, the increase of capital cost is three million yen in the case of one row control and six million yen in the case of two rows control. When the window of a building is small, we can take the advantage of the addition of the step light control because of large increase of saved energy for artificial lighting. On the other hand we don't take the advantage in the case of large window.

(c) We can say that the most economical method of energy saving is the reduction of window area and the second is the construction of eaves. The third economical method is turning on/off system of artificial lighting inside perimeter zone utilizing daylight and the last is turning on/off plus step light control system. However it's evident that the turning on/off system or the same system plus step light control of artificial lighting inside perimeter zone utilizing daylight is also effective in a existing building. 


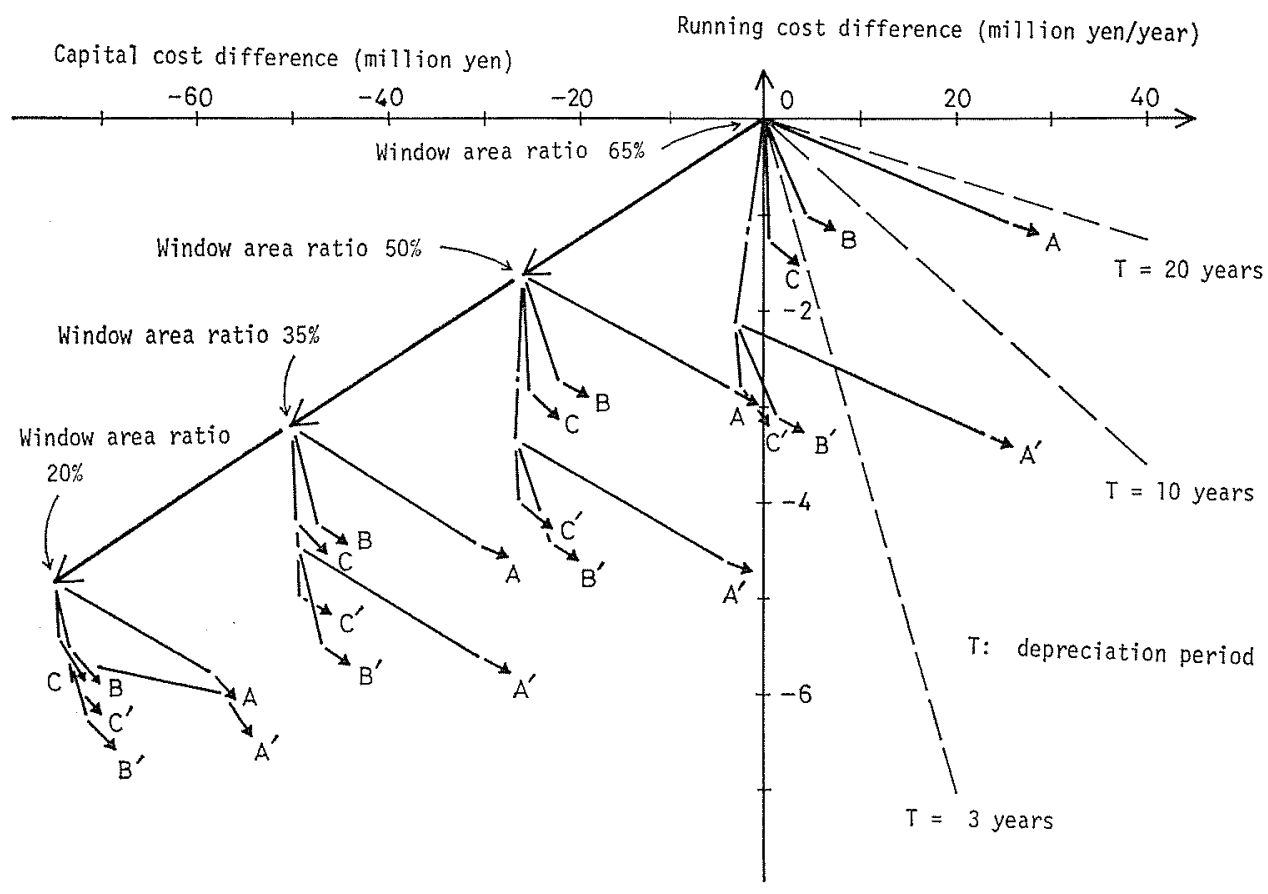

Fig. 8 The analysis of energy conservation effects using thermal economics vectors.

$\Rightarrow$ Vector of window area

- Vector of eaves

- Vector of turning on/off system

$\longrightarrow$ Vector of step light control

Interest rate of loan: $8 \%$

Controlled luminair: one row from window

Length of eaves: $900 \mathrm{~mm}$

energy price increase rate: $10 \%$

$A, A^{\prime}$ : Automatically controlled operation of venetian blind

$B, B^{\prime}$ : Manual operation once $a$ day of venetian blind

$C, C^{\prime}$ : No up/down manipulation of venetian blind

Ref. There are eaves in the case of $A^{\prime}, B^{\prime}$ and $C^{\prime}$.

\section{Conclusion}

This paper has described about the energy saving effect and economical comparison of turning on/off system and the same system plus step light control of artificial lighting inside perimeter zone using the simulation program. We have a plan to study about occupant psychology under these control and estimate the optimum method of artificial lighting control utilizing daylight.

\section{References}

(1) Saito, M., Sato, K. and Yamaishi, T.: Preprint of 1978 Annual Meeting of Illum. Engng. Inst. Japan, page 85 .

(2) Saito, M., Sakai, K. and Endo, K.: Preprint of 1980 Annual Meeting of Illum. Engng. Inst. Japan, page 94.

(3) Fisher, W. S.: CIE XVIII Session page 455.

(4) Kusuda, T.: 3rd Int. sympo. on the use of computers for environmental eng. related to build. (1978) 569.

(5) Matsuo, Y.: Trns, on Environmental Engng. in Architecture No. 1 (1979) 25

(6) Sakai, K., Fukushima, M. and Endo, K.: Trns. of The Society of Heating, Air-Conditioning and Sani- tary Engng. of Japan No. 11 (1979) 107.

(7) Matsuo, Y., Akasaka, H. and Ibamoto, T.: The Society of Heating, Air-Conditioning and Sanitary Engineers of Japan 49-11 (1975) 114.

(8) The Tokyo Electric Power Co., Inc.: The report of Energy Usage in Buildings (1975).

(9) Iwasaki, H., Sakai, K., Fukushima, M. and Yamaguchi, K.: Proceedings of The Second Symposium on the Use of Computers in Building Engng. (1980) 361.

(10) CIE TC-4.2: Vocabulary (Draft), Sunshine Duration (1979).

(11) Architecture and Building Science Architectural Inst. of Japan: Daylighting Design (1970).

(12) Matsuura, K.: Preprint of 1971 Annual Meeting of Illum. Engng. Inst. Japan, page 47.

(13) Matsuura, K.: Preprint of 1977 Autumn Meeting of Architecture and Building Science Architectural Inst. Japan, page 163.

(14) Ito, K., Ohno, H. and Sato, R.: Preprint of 1978 Autumn Meeting of Architecture and Building Science Architectural Inst. Japan, page 71.

(15) Udagawa, M., Kimura, K.: Preprint of $1975 \mathrm{Au}-$ tumn Meeting of Architecture and Building Science Architectural Inst. Japan, page 377.

(16) Komiya, H.: Report No. 21 (1980) of the Technical Research Inst. Ohbayashi-Gumi, Ltd.

Received 6 Sep. 1982; Revision Received 3 Feb. 1983 